\title{
Lymphogranuloma venereum of the rectum in a homosexual man
}

\author{
Case report
}

\author{
ADRIAN MINDEL \\ From the Academic Department of Genitourinary Medicine, Middlesex Hospital Medical School, London
}

SUMMARY A male homosexual presented initially with bloody diarrhoea and a swelling in the left groin, which was unsuccessfully treated with erythromycin. Examination in hospital showed a $\dot{\omega}$ rectal mass and an abcess in the left groin. Histological examination of the rectal mass and a $\vec{\bullet}$ positive lymphogranuloma complement fixation test result confirmed the diagnosis of o

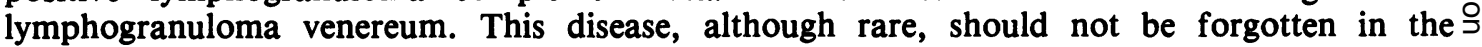
differential diagnosis of rectal problems in male homosexuals.

\section{Introduction}

Lymphogranuloma venereum (LGV) is a tropical sexually transmitted disease (STD). Only 35 cases were seen in the United Kingdom in 1980, most of these infections having been acquired abroad. ${ }^{1}$ Several recent reports from the United States have shown that rectal LGV is now being found among male homosexuals. ${ }^{2-4}$ We report a case of homosexually acquired LGV in the United Kingdom.

\section{Case report}

In December 1981 a 27 year old homosexual clerk noticed diarrhoea, which lasted a week and was followed in early January 1982 by constipation, tenesmus, and rectal bleeding. He attended his general practitioner and was treated symptomatically for haemorrhoids. Though this eased his symptoms they continued intermittently. In mid-January he developed a swelling in the left groin which was treated unsuccessfully with erythromycin by his general practitioner. He was admitted to the Hammersmith Hospital in February.

Examination showed a $6 \times 3 \mathrm{~cm}$ fluctuant nontender abcess in the left groin, which was incised under anaesthesia. Sigmoidoscopy performed at the same time showed an irregular mass situated at 2-5

Address for reprints: Dr A Mindel, Academic Department of Genitourinary Medicine, James Pringle House, Middlesex Hospital Medical School, London WIN 8AA

Accepted for publication 14 December 1982 $\mathrm{cm}$ from the anal margin and covered by thick $\vec{\oplus}$ mucosa which bled profusely. Histological examin- $\omega$ ation showed a severely but patchily inflamed rectal mucosa with a heavy infiltration with inflammatory cells of all types especially plasma cells and several ill defined histiocytic granulomata with multinucleated giant cells. The nature and location of the $\stackrel{\varnothing}{\varrho}$ granulomata were considered atypical for Crohn's $\overrightarrow{\overrightarrow{0}}$ disease, and syphilis was considered a likely 3 diagnosis. He was therefore referred to the $\bar{F}$ department of genitourinary medicine at the Middlesex Hospital where he had previously been 0 treated for rectal gonorrhoea and perianal warts in 1980.

He was seen at the Middlesex Hospital in March and stated that his only sexual contact had been with a Jamaican in November 1981. He had been both the active and the passive sexual partner and had also had orogenital contact. Examination showed an $\frac{D}{0}$ unhealed wound of $3 \mathrm{~cm}$ in the left groin; the findings on proctoscopy were as before.

\section{SPECIAL INVESTIGATIONS}

A rectal smear showed numerous polymorpho- $\omega$ nuclear leucocytes and no Gram negative diplococci. Rectal culture results for Neisseria gonorrhoeae, herpes simplex virus, and Chlamydia trachomatis were negative. Cultures from the groin wound for $C^{-}$ trachomatis and bacteria also gave negative results. $\frac{T}{0}$ Treponemes were not seen on dark ground $\underset{\mathbb{D}}{\circ}$ microscopy of material from the rectal mass; sero- $\frac{\Omega}{\square}$

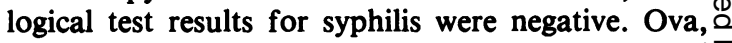
cysts, and parasites were not seen on stool? 
microscopy. The erythrocyte sedimentation rate was $2 \mathrm{~mm}$ in the first hour and the white blood cell count $11 \times 10^{9} / 1$ (70\% neutrophils). Estimation of urea, electrolytes, and liver function and a barium enema also showed no abnormalities. The lymphogranuloma complement fixation test (LGV-CFT) was positive at a titre of 512 , which is compatible with an acute LGV infection.

\section{TREATMENT AND FOLLOW UP}

The patient was treated with oral oxytetracycline 500 $\mathrm{mg}$ four times daily for three weeks. The inguinal operation site healed within a week and the rectal mass completely resolved after three weeks. After three months the LGV-CFT was still positive at a titre of 32, and the serological test results for syphilis remained negative.

\section{Discussion}

Chlamydial infection of the rectum causes a wide range of symptoms. Many patients are asymptomatic, some have a diffuse proctitis, and a few with LGV have granulomatous masses in the rectum. ${ }^{4}$ Though rectal LGV has been recognised for many years, early reports of cases were predominantly in women and were considered to be a late complication of genital infection, either by lymphatic spread or "spill" during sexual intercourse. ${ }^{5}$ Cases of homosexually acquired LGV were reported from Seattle $^{4}$ in three men with proctitis. The clinical features of these cases were similar to the present one, though they differed in one respect. Whereas the patients in Seattle were promiscuous homosexuals our patient had had sexual contact with only one partner in the previous three months.

The differential diagnosis of inflamed rectal mucosa with or without masses or ulcers in homosexuals includes Crohn's disease, amoebiasis, syphilis, gonorrhoea, carcinoma, ulcerative colitis, and infection with herpex simplex virus, Yersinia spp, Campylobacter spp, and Clostridium difficile. Though LGV is extremely rare in Britain ${ }^{1}$ it should not be forgotten as part of the differential diagnosis.

\section{References}

1. Communicable Disease Surveillance Centre and the Academic Department of Genito Urinary Medicine, Middlesex Hospital. Sexually transmitted disease surveillance $1980 . \mathrm{Br}$ Med $J$ 1982;284: 124.

2. Levine JS, Smith PD, Brugge WR. Chronic proctitis in male homosexuals due to lymphogranuloma venereum. Gastroenterology 1980; 79:563-5.

3. Schachter J. Confirmatory serodiagnosis of lymphogranuloma venereum proctitis may yield false-positive results due to other chlamydial infections of the rectum. Sex Transm Dis 1981;8:26-8.

4. Quinn TC, Goodell SE, Mkrtichian E, et al. Chlamydia trachomatis proctitis. N Engl J Med 1981;305: 195-200.

5. Miles RPM. Rectal lymphogranuloma venereum. Postgrad Med J 1959; 35: 92-6. 